\title{
Predator-mediated Allee effects in multi-prey systems
}

\author{
Bruce N. Mclellan, ${ }^{1}$ Robert Serrouya, ${ }^{1,2}$ Heiko U. Wittmer,,${ }^{3,4}$ and Stan Boutin ${ }^{2}$ \\ ${ }^{1}$ British Columbia Ministry of Forests and Range, RPO \#3, P.O. Box 9158, Revelstoke, British Columbia V0E 3 KO Canada \\ ${ }^{2}$ Department of Biological Sciences, University of Alberta, Edmonton, Alberta T6G 2 E9 Canada \\ ${ }^{3}$ Wildife, Fish, and Conservation Biology, University of California, One Shields Ave., Davis, California 95616 USA
}

Abstract. Allee effects can have significant consequences for small populations and understanding the causal mechanisms for such effects is important for guiding conservation actions. One proposed mechanism is through predation, in which a type II functional response leads to increasing predation rates as prey numbers decline. However, models to support this mechanism have incorporated only a single declining prey species in the functional response, which is probably an oversimplification. We reevaluated the potential for predator-mediated Allee effects in a multi-prey system using Holling's disc equation. We also used empirical data on a large herbivore to examine how grouping behavior may influence the potential for predation-mediated Allee effects. Results based on a multi-prey expression of the functional response predict that Allee effects caused by predation on relatively rare secondary prey may not occur because handling time of the abundant prey dominates the functional response such that secondary prey are largely "bycatch." However, a predator-mediated Allee effect can occur if secondary prey live in groups and if, as the population declines, their average group size declines (a relationship seen in several species). In such a case, the rate at which the number of groups declines is less than the rate at which the population declines. Thus the rate at which a predator encounters a group remains relatively stable, but when a predator kills one animal from smaller groups, the predation rate increases. These results highlight the need to evaluate risks associated with potential changes in group size as populations decline.

Key words: Allee effect; apparent competition; conservation; functional response; mountain ecotype woodland caribou; predator-prey interactions; Rangifer tarandus caribou; social organization; southeastern British Columbia, Canada.

\section{INTRODUCTION}

Understanding mechanisms affecting small populations is critical for implementing effective conservation actions. Of particular importance for conservation are possible Allee effects (or inverse density dependence) that cause the per capita growth rate to decline as populations become smaller (Allee et al. 1949, Courchamp et al. 1999, Stephens et al. 1999). Allee effects greatly exacerbate extinction risk unless appropriate management is applied.

Documented mechanisms causing Allee effects include an insufficient number of conspecifics for efficient reproduction or predator avoidance (Courchamp et al. 1999, 2008, Stephens et al. 1999). Several studies have concluded that a predator-mediated Allee effect may be common when a predator displays a type II functional response in combination with, or in particular without, a numerical response to declines in the density of the rare prey species (Sinclair et al. 1998, Cantrell et al. 2001, Gascoigne and Lipcius 2004, Wittmer et al. 2005b, Angulo et al. 2007, Courchamp et al. 2008). The lack of

Manuscript received 18 February 2009; revised 28 April 2009; accepted 30 April 2009. Corresponding Editor: M. FestaBianchet.

${ }^{4}$ Corresponding author. E-mail: huwittmer@ucdavis.edu a numerical response by the predator could arise where the rare prey species is declining, but because it is a minor component in the diet of the predator, the predator shows no change in number associated with its decline. It has been suggested that under such a scenario, the type II functional response alone is capable of creating an escalating mortality rate of prey as their numbers decline, thus causing an Allee effect (Sinclair et al. 1998, Gascoigne and Lipcius 2004).

In their recent book entitled "Allee effects in ecology and conservation," Courchamp et al. (2008:109) point out "although single species models have been very useful for understanding Allee effects, their failure to account for interspecific relationships is in many cases an oversimplification." We agree that this is the case when considering predator-mediated Allee effects. Although the implications of various combinations of functional and numerical responses have been discussed in detail (e.g., Holling 1959a, Oaten and Murdoch 1975, Messier 1995), these investigations were based on singleprey systems or at least were focused on the dominant prey species in the system. However, the potential for an Allee effect is only relevant to prey that are a small component of the total biomass available to the predator in the multi-prey system. Otherwise, the predator would probably show a conventional numerical response, negating the potential for an Allee effect. 
Our objectives are twofold. First, we reevaluate predictions involving predator-mediated Allee effects (Messier 1995, Sinclair et al. 1998, Gascoigne and Lipcius 2004) by including multiple prey species in the functional response. We are interested in the situation in which predators forage on declining rare prey (i.e., secondary prey) but spend the majority of their time eating more abundant primary prey (Bergerud and Elliot 1986, Seip 1992, Robinson et al. 2002, Wittmer et al. 2005b). Others have recognized that the relationship between predators and prey depends not only on their abundance, but also on the social organization of the various species involved (e.g., Hamilton 1971, Fryxell et al. 2007). Therefore, our second objective was to examine how group size changes with population density and how this, in turn, affects predation rates under scenarios of declining secondary prey. We use data from the endangered mountain ecotype of woodland caribou (Rangifer tarandus caribou), which is declining in numbers over most of its distribution (Wittmer et al. 2005a).

\section{Methods \\ Functional response model}

If prey did not live in groups and were part of a singlepredator-single-prey system, the type II functional response of that predator would follow the "disc equation" of Holling (1959b):

$$
y_{\mathrm{t}}=\frac{a N T}{1+a N T_{\mathrm{h}}}
$$

where $y_{\mathrm{t}}$ is the total number of prey killed per predator over a total period of time $T, a$ is the searching rate of the predator, $N$ is the prey density, and $T_{\mathrm{h}}$ is the handling time that includes chasing, killing, consuming, and digesting one prey. The mortality rate of the prey caused by predation (i.e., predation rate) can then be determined from the number of prey killed divided by the prey population size (Messier 1994). The number of prey killed is referred to as the "total response" and is simply the product of the functional and numerical response (Holling 1959a, Messier 1994).

If there is more than one prey species (in the following example we use two prey species) and, for simplicity, all prey species have the same handling time, $N$ becomes the sum of the number of each species (sensu Abrams 1990), and

$$
y_{\mathrm{t}}=\frac{a\left(N_{1}+N_{2}\right) T}{1+a\left(N_{1}+N_{2}\right) T_{\mathrm{h}}}
$$

where $y_{\mathrm{t}}$ is now the total number of both prey species killed per predator. If, for this simple model, we assume that the predator encounters prey in proportion to their abundance and, once encountered, the probability of killing is the same for each species, then we can divide $y_{\mathrm{t}}$ into $y_{1}$ and $y_{2}$, the numbers of each prey species killed, based on their relative abundance.
Prey living in groups

If one of the species is found in groups, then $N_{i}$ is the number of groups, not individuals. What is critical in the group-size component of our model is that we assume the probability of a searching predator encountering a group is equal to encountering an individual (see Huggard 1993) and the predator kills only one group member at a time. These assumptions are unlikely true for all predator-prey systems, but are more likely to hold when the secondary prey are rare and exist in small groups (where Allee effects are expressed) and handling time is of sufficient duration to enable surviving members of the group to effectively escape (e.g., Huggard 1993, Hebblewhite and Pletscher 2002, Fryxell et al. 2007, Coleman 2008). For group sizes and thus number of groups $\left(N_{i}\right)$ used in Eq. 2 to estimate predation rates at various population sizes, we first used the relationship between the average population size determined by Wittmer et al. (2005a) and observed groups sizes of mountain caribou in summer (see Field data).

For all models, we use a handling time of 5 days per prey item and a search rate of $1 \mathrm{~km}^{2} / \mathrm{d}, T$ is $30 \mathrm{~d}$, and the prey density is number of individuals $/ 1000 \mathrm{~km}^{2}$. In the single-prey models, we vary their numbers between 1 and 300. For the multi-prey models, we vary the numbers of secondary prey between 1 and 300 while keeping the primary prey stable at 1000 . We first use a type 0 numerical response (i.e., no response) because we are interested in Allee effects of small populations. To enable further comparisons and because we varied the ratio of primary to secondary prey considerably in our models, we also incorporated a simple type I numerical response. The type I numerical response is based on one predator per 50 prey groups (i.e., a linear response to prey density; e.g., Fuller 1989).

To investigate implications of animal group sizes beyond data available from caribou, we used Eq. 2 but varied the slope and shape of the relationship between group size and population size of the secondary prey, while keeping the number of primary prey stable at 1000 solitary animals. To maintain simplicity and because it was the suggested relationship for some species, we varied the slope $(b)$ of the line (group size $\left.=1+b N_{2}\right)$ to have group sizes of $1,2,5$, and 10 animals when there were 300 secondary prey but always 1 when the last animal remained.

\section{Field data}

Mountain caribou live in a multi-prey-multi-predator system in southeastern British Columbia, Canada, that includes up to seven other ungulate species that are preyed on by up to five carnivore species (for a detailed map of the study area and description of the physical environment, see Wittmer et al. 2005a). Mountain caribou have been studied using radiotelemetry since 1984 and individuals from 18 populations have been monitored; however, four populations were so small and infrequently seen in summer that insufficient group size 

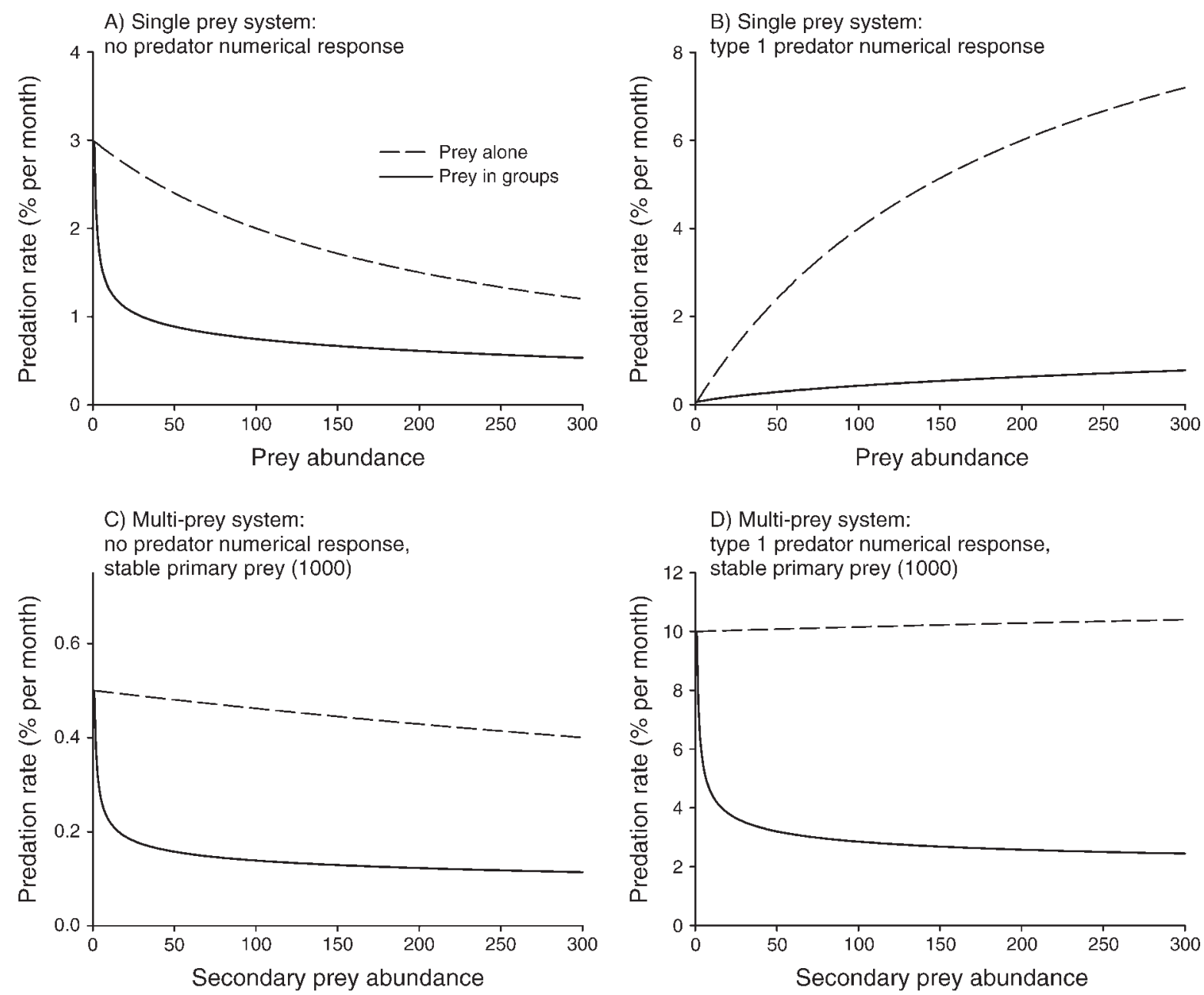

FIG. 1. Predation rates (percentage of the population preyed on each month) for prey that live alone (dashed lines) or in groups (solid lines) for: (A) single prey species at different levels of abundance (1-300 individuals) with a type II functional response and no numerical response from the predator; (B) single prey species (1-300 individuals) with a type II functional response and a type I predator numerical response; (C) secondary prey species (1-300 individuals) with a type II functional response, but when the predator's primary prey population is stable (1000), and with no numerical response from the predator; (D) secondary prey species (1-300 individuals) with a type II functional response and a type I numerical response, but when the predator's primary prey population is stable (1000).

data were obtained and data from one population were not available for our analysis. Thus, data from 13 populations were available to determine the relationship between population size and group size.

Collared animals were located 2-4 times per month from a fixed-wing aircraft and the number of animals in the group was recorded whenever they were observed. Populations were censused from helicopters in March or early April, when caribou are in open, high-elevation habitats, and shortly after new snow fell (Wittmer et al. 2005a). The relationship between the average size of the population and mean group size was made for the summer season when caribou habitat overlaps with alternative prey and predators and that is when most predation occurs (Wittmer et al. 2005a).

To determine if the relationship between population size and group size is limited to mountain caribou and therefore not of broader utility, we also used data from moose (Alces alces; sampled within the central portion of the mountain caribou distribution) and elk (Cervus elaphus; sampled in neighboring Banff National Park, Alberta, Canada). For both of these species, winter censuses from helicopter provided group sizes and population estimates that varied over time. We did not use moose and elk data for our modeling, but rather to determine if the group size relationship holds beyond caribou.

\section{RESUlts}

\section{Modeling predation rates with prey living alone}

In a single-prey system, the type II functional response model shows an Allee effect if prey live alone and the predator has no numerical response (Fig. 1A, prey alone). When we added a type I numerical response 

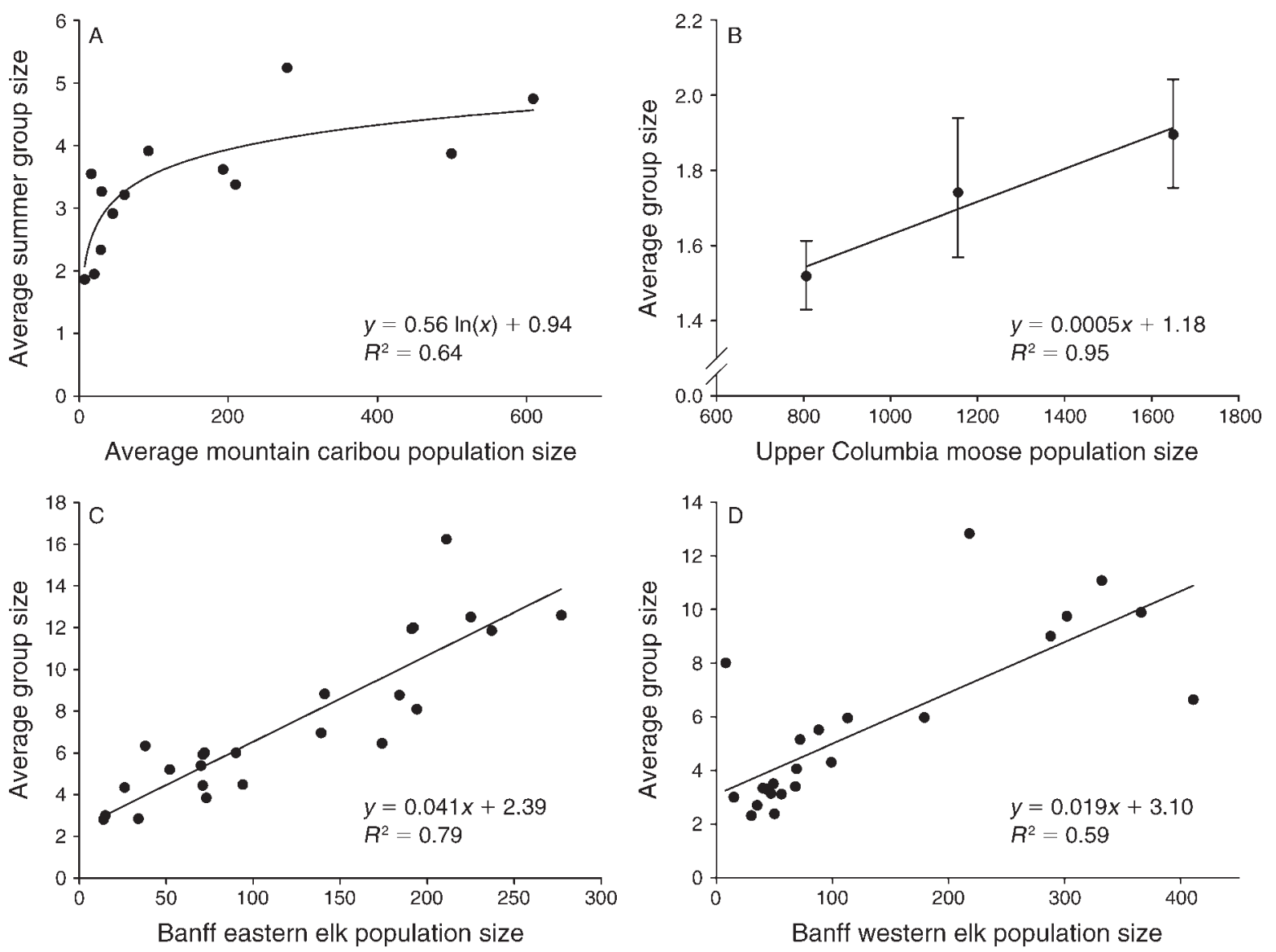

FIG. 2. Relationship between the size of populations and average group sizes. (A) Mountain caribou population sizes and average group sizes observed in summer. (B) Population size and average group size of Upper Columbia moose population (error bars are 95\% CI, shown here because only three data points). (C) Population size and average group size of Banff eastern elk population. (D) Population size and average group size of Banff western elk population (adapted from Hebblewhite and Pletscher [2002]).

to the type II functional response the Allee effect disappeared (Fig. 1B, prey alone); that is, the predation rate declined as the population declined because there were fewer predators. In a multi-prey system with primary prey that are stable and abundant (1000), and a rarer (0-300), declining secondary prey and no predator numerical response to either prey, the Allee effect on the secondary prey was weaker than in the single-prey scenario (Fig. 1A vs. C, prey alone). The predation rate actually changed very little as the rare prey declined. Because the magnitude of this Allee effect is proportional to the ratio of secondary prey to the sum of both secondary and primary prey, it would have been even less if primary prey were more abundant. If a type I numerical response were added (for both prey), the weak Allee effect on the secondary prey would disappear (Fig. $1 \mathrm{D}$, prey alone).

\section{Prey living in groups: field data and models of predation rates with groups}

To make model predictions with group-living organisms, we first needed to determine how group size changes with population size and we used field data to obtain this empirical relationship. Between 1984 and 2006, 541 caribou were radio-collared and 2099 groups were seen during the summer season, when the average group size was 3.8 individuals and $95 \%$ of groups had $<10$ members. Mean group sizes of mountain caribou were significantly larger in the larger populations, although the relationship was logarithmic (GLM caribou: $R^{2}=0.64, F_{1,11}=19.15, P=0.001$; Fig. $2 \mathrm{~A}$ ). The largely solitary moose show a similar trend (bootstrapped 95\% CIs do not overlap; Fig. 2B). The magnitude of change was strongest for elk (Fig. 2C, D; GLM Eastern Banff: $R^{2}=0.79, F_{1,22}=80.42, P=0.001$; GLM Western Banff: $R^{2}=0.59, F_{1,22}=31.35, P=$ $0.001)$. Moose and elk were not used in model scenarios, but simply to ensure that the relationship is not limited to caribou.

In all cases, the group-living scenario resulted in lower predation rates (Fig. 1). With a single group-living prey and no numerical response, there was an Allee effect that became most pronounced at $<50$ animals (Fig. 1A, groups). When we add the numerical response, the Allee effect again disappeared (Fig. 1B, groups). In the multispecies scenario, however, the Allee effect existed 

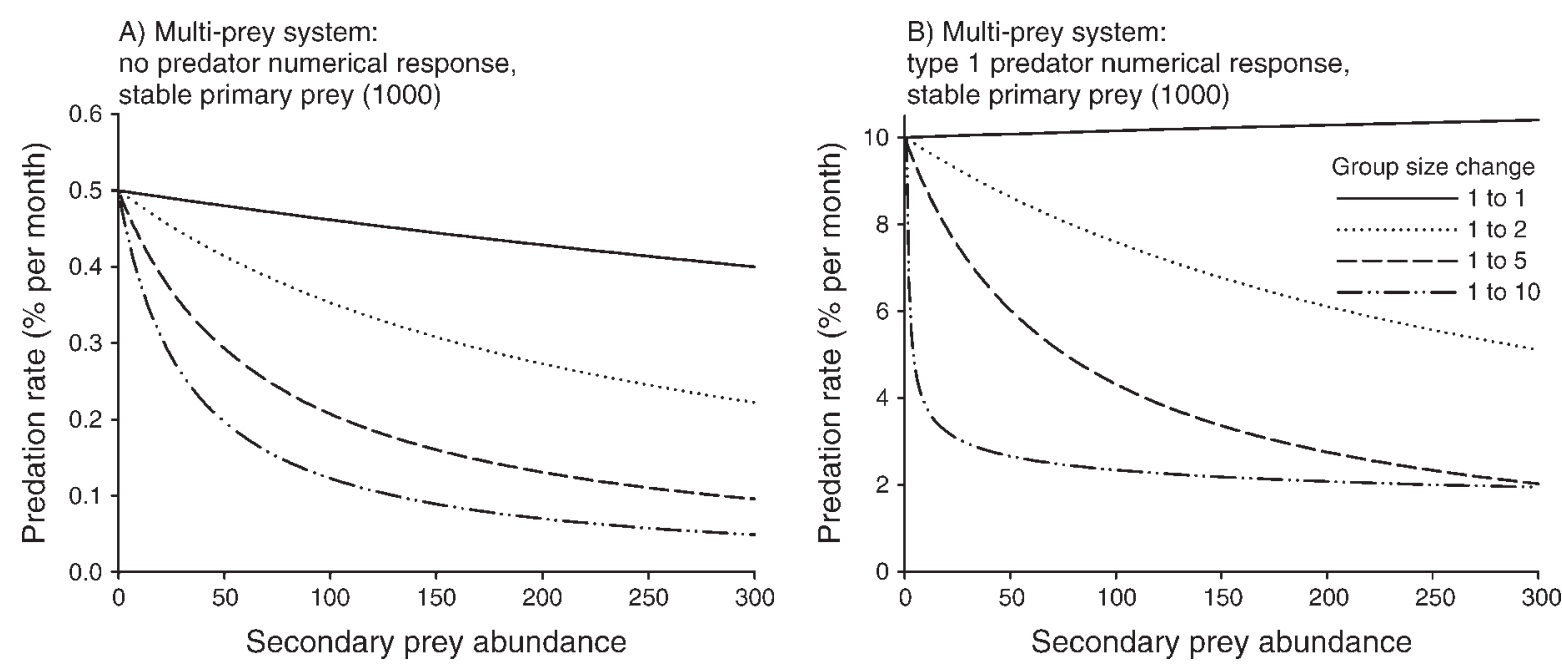

FIG. 3. The effect of various linear relationships between group size and population size (group size $=1+b N_{2}$, where $b$ is the slope) on the predicted predation rate of a secondary prey species with a type II functional response but when the predator's primary prey population is stable and maintained at 1000 animals. Predation rate is the percentage of the population preyed on each month. The linear relationship varied from 1 animal per group at all population sizes (solitary species) to where group sizes increased from 1 to 2,1 to 5 , and 1 to 10 animals per group when there were 300 individuals in the population. In (A), there is no numerical response. In (B) there is a type I predator numerical response to the number of groups.

regardless of whether the predator did or did not show a numerical response (Fig. 1C, D, groups). The strength of the Allee effect increased the more the group size declined with declining population size (Fig. 3).

\section{DisCUSSION}

It is now common to find situations in which declining, rare prey species are subject to elevated predation rates because predators are sustained by other primary prey (e.g., Seip 1992, Holt and Lawton 1994, Sweitzer et al. 1997, Sinclair et al. 1998, Norbury 2001, Robinson et al. 2002). In some instances, the declining prey appears to be subject to an Allee effect (Sinclair et al. 1998, Wittmer et al. 2005b). Previous theoretical modeling of predator-mediated Allee effects considered only the rare, secondary prey species in the functional response of the predator. With a single prey species and no numerical response to the number of prey, our results, like those of Gascoigne and Lipcius (2004), predict a strong Allee effect. However, conditions for this scenario would be rare and may be limited to situations such as where exotic predators are preying on a species that has not evolved a predator avoidance strategy. Under this scenario, a predator may kill all individuals of the species quickly without switching to other prey species. It is probably more common, however, that the rare prey are but one of several prey species, and it is here that predictions of our functional response model differ from those of Messier (1995), Sinclair et al. (1998), and Gascoigne and Lipcius (2004).

\section{Multiple prey species in the functional response}

Given that the basis of the disc equation is the change in time that a predator spends handling and searching for prey at different prey densities (Holling 1959b), all prey species should be included. Limiting the functional response to just the rare species that is suffering an Allee effect assumes that predators are spending enough time handling this species to affect predation rates to a significant degree. It also assumes that a change in the number of primary prey will not affect the number of the secondary species that an individual predator will kill. This is clearly not true. If the number of primary prey greatly increases, then each predator will spend less time searching and more time handling primary prey than before. Conversely, if the number of primary prey declines, then each predator will spend more time searching and handling secondary prey than before. Combining all prey species into the disc equation causes the more common prey to dominate the functional response, or the amount of time a predator spends handling and searching for prey. This modification only required summing values of both prey species for the density and handling time expressed in Holling's (1959b) disc equation.

When we modified the functional response to include an abundant but stable primary prey, our model predicted a very weak Allee effect when there is no numerical response and no Allee effect with a type I numerical response. In both cases, if there is an abundance of primary prey, the predation rate on the secondary prey is essentially density independent (i.e., "bycatch"). In other words, changes in density of the secondary prey species have little effect on the predation rate that it experiences. This result differs from those of Messier (1995: Fig. 4b), Gascoigne and Lipcius (2004), and Sinclair et al. (1998), who used only one species in the functional response and a variety of ways to account 
for a numerical response. However, it is important to emphasize that "bycatch" of secondary prey can still lead to extirpation by predators that are sustained by abundant primary prey (i.e., apparent competition; Holt and Lawton 1994) despite the absence of an Allee effect.

\section{Prey living in groups with changing group size}

All of our models show that grouping behavior reduces predation rates, which is consistent with abundant theoretical and empirical work (e.g., Hamilton 1971, Clutton-Brock et al. 1999, Mooring et al. 2004, Fryxell et al. 2007). However, the mechanism that we reveal is how an Allee effect could occur by including the effect of declining group size with declining population size. The underlying reason for this type of Allee effect is that the number of groups declines more slowly than the total population size. Thus the rate at which groups are encountered may remain relatively stable, but when one animal is killed from smaller groups, the predation rate increases. As a consequence, any individual in smaller groups is more likely to be killed by a predator encountering the group. This explanation is likely to account for some of the Allee effect observed in caribou in southeastern British Columbia (Wittmer et al. 2005b), where declining populations have resulted in smaller group sizes (the Allee effect is probably not due to difficulty finding mates, because pregnancy rates are high $(92 \%)$ and invariant across all densities [Wittmer et al. 2005a]). Because a variety of species appear to be found in smaller groups when population sizes decline (e.g., Vincent et al. 1995, Borkowski 2000, McConville et al. 2009), this mechanism may be common but appears to have been overlooked in the Allee literature. For example, Courchamp et al. (2008:40) reported that caribou studied by Wittmer et al. (2005b) were prey "without gregarious behaviour," even though Wittmer et al. (2005b:265) posit this mechanism: "because arboreal-lichen feeding woodland caribou live in groups ... the predation rate on smaller populations with smaller groups would be higher."

Although our models make several simplifying assumptions, this approach was deliberate to make direct comparisons to previous work that made similar assumptions (i.e., constant $a$ and $T_{\mathrm{h}}$ across a range of prey density and simple, instantaneous numerical response). We make the additional assumption that the encounter rate for group-living animals is the same as animals that live alone. This is unlikely to be correct across a broad range of group sizes (Hebblewhite and Pletscher 2002). However, the magnitude of change in group size in our system is only 4.5 to 1 , and in a forested ecosystem it is unlikely that this would have an influence on encounter rates, particularly for a rare species. In support of this approach, Fryxell et al. (2007:1041) point out that "each doubling of prey density leads to a much more modest increase in encounter frequency with groups."
In summary, our models suggest that, contrary to previous theory, Allee effects on relatively rare declining prey are weak or nonexistent in multi-prey systems where functional responses of the predator are dominated by handling primary prey. However, if prey live in groups and group size declines as prey density declines, then this can contribute to an Allee effect. These results highlight the need to evaluate risks associated with potential changes in group size as populations decline. In addition, population augmentations could be used as a tool to increase group sizes of resident populations of social ungulates to levels that reduce the potential effect of predators (Mooring et al. 2004). Alternatively, the level of predator management required to recover a group-living species may be different from that for species that live alone or if group size is not related to population size. More empirical studies are required to test our prediction of the relationship between rates of decline and group size in social animals, including ungulates.

\section{ACKNOWLEDGMENTS}

We thank D. Seip, T. Kinley, D. Hamilton, J. Young, and G. Watts for sharing caribou data. Jesse Whittington kindly provided the elk data. Numerous additional people were involved in data collection. D. Armstrong, J. Fryxell, D. Huggard, M. Lewis, P. Stephens, and an anonymous reviewer provided helpful comments on earlier versions of this manuscript.

\section{Literature Cited}

Abrams, P. A. 1990. The effects of adaptive behavior on the type-2 functional response. Ecology 71:877-885.

Allee, W. C., O. Park, A. E. Emerson, T. Part, and K. P. Schmidt. 1949. Principles of animal ecology. Saunders, Philadelphia, Pennsylvania, USA.

Angulo, E., G. W. Roemer, L. Berec, J. Gascoigne, and F. Courchamp. 2007. Double Allee effects and extinction in the island fox. Conservation Biology 21:567-577.

Bergerud, A. T., and J. P. Elliot. 1986. Dynamics of caribou and wolves in northern British Columbia. Canadian Journal of Zoology 64:1515-1519.

Borkowski, J. 2000. Influence of the density of a sika deer population on activity, habitat use, and group size. Canadian Journal of Zoology 78:1369-1374.

Cantrell, R. S., C. Cosner, and W. F. Fagan. 2001. How predator incursions affect critical patch size: the role of the functional response. American Naturalist 158:368-375.

Clutton-Brock, T. H., D. Gaynor, G. M. McIlrath, A. D. C. Maccoll, R. Kansky, P. Chadwick, M. Manser, J. D. Skinner, and P. N. M. Brotherton. 1999. Predation, group size and mortality in a cooperative mongoose, Suricatta suricatta. Journal of Animal Ecology 68:672-683.

Coleman, R. A. 2008. Overestimations of food abundance: Predator responses to prey aggregation. Ecology 89:17771783.

Courchamp, F., L. Berec, and J. Gascoigne. 2008. Allee effects in ecology and conservation. Oxford University Press New York, New York, USA.

Courchamp, F., T. Clutton-Brock, and B. Grenfell. 1999. Inverse density-dependence and the Allee effect. Trends in Ecology and Evolution 14:405-410.

Fryxell, J. M., A. Mosser, A. R. E. Sinclair, and C. Packer. 2007. Group formation stabilizes predator-prey dynamics. Nature 449:1041-1044. 
Fuller, T. K. 1989. Population dynamics of wolves in northcentral Minnesota. Wildlife Monographs 105.

Gascoigne, J. C., and R. N. Lipcius. 2004. Allee effects driven by predation. Journal of Applied Ecology 41:801-810.

Hamilton, W. D. 1971. Geometry for the selfish herd. Journal of Theoretical Biology 31:295-311.

Hebblewhite, M., and D. Pletscher. 2002. Effects of elk group size on predation by wolves. Canadian Journal of Zoology 80:800-809.

Holling, C. S. 1959a. The components of predation as revealed by a study of small-mammal predation of the European sawfly. Canadian Entomologist 91:293-320.

Holling, C. S. 1959b. Some characteristics of simple types of predation and parasitism. Canadian Entomologist 91:385398.

Holt, R. D., and J. H. Lawton. 1994. The ecological consequences of shared natural predators. Annual Reviews in Ecology and Systematics 25:495-520.

Huggard, D. J. 1993. Prey selectivity of wolves in Banff National Park 1. Prey species. Canadian Journal of Zoology 71:130-139.

McConville, A. J., Iu. A. Grachev, A. Keane, T. Coulson, A. B. Bekenov, and E. J. Milner-Gulland. 2009. Reconstructing the observation process to correct for changing detection probability of a critically endangered species. Endangered Species Research 6:231-237.

Messier, F. 1994. Ungulate population models with predation: a case study with the North American moose. Ecology 75: $478-488$.

Messier, F. 1995. On the functional and numerical responses of wolves to changing prey density. Pages 187-198 in L. N. Carbyn, S. H. Fritts, and D. R. Seip, editors. Ecology and conservation of wolves in a changing world. Canadian Circumpolar Institute, Edmonton, Canada.

Mooring, M. S., T. A. Fitzpatrick, T. T. Nishihira, and D. D. Reisig. 2004. Vigilance, predation risk, and the Allee effect in desert bighorn sheep. Journal of Wildlife Management 68: $519-532$.
Norbury, G. 2001. Conserving dryland lizards by reducing predator-mediated apparent competition and direct competition with introduced rabbits. Journal of Applied Ecology 38:1350-1361.

Oaten, A., and W. W. Murdoch. 1975. Functional response and stability in predator-prey systems. American Naturalist 109: 289-298.

Robinson, H. S., R. B. Wielgus, and J. C. Gwilliam. 2002. Cougar predation and population growth of sympatric mule deer and white-tailed deer. Canadian Journal of Zoology 80: $556-568$.

Seip, D. R. 1992. Factors limiting woodland caribou populations and their interrelationships with wolves and moose in southeastern British Columbia. Canadian Journal of Zoology 70:1494-1503.

Sinclair, A. R. E., R. P. Pech, C. R. Dickman, D. Hik, P. Mahon, and A. E. Newsome. 1998. Predicting effects of predation on conservation of endangered prey. Conservation Biology 12:564-575.

Stephens, P. A., W. J. Sutherland, and R. P. Freckleton. 1999. What is the Allee effect? Oikos 87:185-190.

Sweitzer, R. A., S. H. Jenkins, and J. Berger. 1997. Nearextinction of porcupines by mountain lions and consequences of ecosystem change in the Great Basin Desert. Conservation Biology 11:1407-1417.

Vincent, J. P., E. Biedeau, A. J. M. Hewison, and J. M. Angibault. 1995. The influence of increasing density on body weight, kid production, home range, and winter grouping in female roe deer. Oecologia 103:302-308.

Wittmer, H. U., B. N. McLellan, D. R. Seip, J. A. Young, T. A. Kinley, G. S. Watts, and D. Hamilton. 2005a. Population dynamics of the endangered mountain ecotype of woodland caribou (Rangifer tarandus caribou) in British Columbia, Canada. Canadian Journal of Zoology 83:407418.

Wittmer, H. U., A. R. E. Sinclair, and B. N. McLellan. $2005 b$. The role of predation in the decline and extirpation of woodland caribou. Oecologia 144:257-267. 